\title{
FORUM
}

\section{The Graduation of Compass Cards}

\author{
W. E. May
}

I RECENTLY received from a correspondent on the other side of the Atlantic a request for information concerning the graduation of compass cards. I compiled the following notes which may be of some interest to readers of the Journal. I must, however, point out that to a great extent they are based on examination of compasses and cards in museums and on my own experience. It may well be that readers, especially those from other countries, may be able to supplement or correct my statements. Any such information would be most welcome.

The earliest compass cards were graduated in points and quarter points, based on eight wind names in the Mediterranean and four in northern countries. The Finns seem to have based their system on six names. 1 When a requirement arose for finer graduations the obvious arrangement was to divide the card into four quadrants of $90^{\circ}$ each and this scheme seems to have been adopted by all nations, first for azimuth compass cards and later for steering cards as well. I have seen $90^{\circ}$ cards from the United Kingdom, France, Spain, Italy, the Netherlands, Germany, Denmark and Russia, and S. A. Bellini in Early American Scientific Instruments and their Makers (Smithsonian, 1964) shows that they were in common use in the United States as well.

A few scientific men suggested a $360^{\circ}$ card, notably Petrus Peregrinus in 1269 and Robert Dudley in 1646 , but the idea does not seem to have been adopted.

In 1840 the Admiralty produced the famous Admiralty Standard Compass. This was intended as a surveying instrument as well as a ship's compass and for this reason the card had $90^{\circ}$ and $360^{\circ}$ graduations as well as points. The $360^{\circ}$ graduation of this card was never used in navigation. About 1910 the Royal Navy began experimenting with gyro-compasses, trying first the German Anschütz and later the American Sperry. In each case a $360^{\circ}$ graduation was used following the custom of their respective navies for magnetic compass cards. As gyro-compasses came into general use it was suggested that the $360^{\circ}$ graduation should be adopted for magnetic cards also, but it was finally decided that it would avoid much confusion if the $360^{\circ}$ notation were used for true and gyro-compass courses and bearings only, and the $90^{\circ}$ notation retained for magnetic.

Some Merchant Navy officers took a different view and $360^{\circ}$ cards were becoming increasingly common in merchant vessels between the wars.

When World War II broke out the Royal Navy was therefore still using $90^{\circ}$ cards though the point graduations, except for the eight principal points, had been abandoned. Magnetic compasses were among the stores supplied from this country to the rapidly expanding Royal Canadian Navy and these cards had of course the $90^{\circ}$ graduation. Many of their officers were accustomed to the American practice and bitterly resented these cards, though no one seems to have complained to the Admiralty. Instead some enterprising individuals opened up their compasses and altered the cards in ink. The bowls subsequently leaked

1 This Journal, 6, 248. 
and had to be returned. Enquiries were made, the whole matter was discussed over again and it was finally decided that the Royal Navy should go over to $360^{\circ}$ cards.

I have seen a French naval card from before 1870 which has a $360^{\circ}$ graduation, but I believe this to be a rare specimen. The light type dry cards which they were using at the turn of the century had the $90^{\circ}$ graduation and I imagine that they changed to $360^{\circ}$ when they adopted liquid compasses shortly before World War I, the Italian Navy doing the same.

The United States Navy was still using $90^{\circ}$ cards about i 880 and probably changed to $360^{\circ}$ about 1900 , as did the Germany Navy.

One of the most conservative bodies of seamen were British fishermen, who were still often to be found between the wars using cards marked in points without any degrees.

\section{Radar and the Rule of the Road}

\section{Captain W. Burger and Captain A. G. Corbet}

THE following amendments and additions to the existing (1960) Regulations for Preventing Collisions at Sea are offered for comment by Institute members and others interested in this problem.

The only comment which we wish to make about them at this time is that we do not claim that any of the ideas on which these suggested new rules are based are our original ideas-they have only been sorted out, into what we hope will prove to be a satisfactory arrangement, from many ideas which have come to light and have been aired during exercises and discussions that have taken place during radar simulator courses conducted at the Welsh College of Advanced Technology over the last five years and during discussions with many members of the staffs of other nautical colleges and with nautical surveyors of the Board of Trade. The ideas put forward by many notable persons in the various nautical publications have also been studied and have greatly influenced us.

The reason why we do not wish to comment on the suggested rules further than this at this stage is because we are hoping, perhaps rather wishfully, that they have no real weaknesses, are completely self-explanatory and thus do not really require pages and pages of interpretation and expansion to make them clear. Wishful indeed!

Rule 16

(a) Unchanged.

(b) A power-driven vessel hearing, apparently forward of her beam, the fog signal of a vessel, the position of which is not fully ascertained by sighting, shall, so far as the circumstances of the case admit, stop her engines and navigate with particular caution until danger of collision is over.

(c) (i) A power-driven vessel which detects, by radar, the presence of another 